\title{
Sucrose dilution of glycerol from mouse embryos frozen rapidly in liquid nitrogen vapour
}

\author{
A. Széll and J. N. Shelton \\ Department of Immunology, The John Curtin School of Medical Research, Australian National \\ University, P.O. Box 334, Canberra 2601, A.C.T., Australia
}

\begin{abstract}
Summary. The toxic effects of sucrose and the conditions of in-straw glycerol removal after freezing and thawing were studied using Day-3 mouse embryos. At $20^{\circ} \mathrm{C}$, exposure to $\leqslant 1.0 \mathrm{M}$-sucrose for periods up to $30 \mathrm{~min}$ had no adverse effects on freshly collected embryos. At 25 and $36^{\circ} \mathrm{C}$, however, $\geqslant 1.0 \mathrm{M}$-sucrose significantly reduced the developmental potential $(P<0.001)$.

In the freezing experiments the embryos were placed in $0.5 \mathrm{ml}$ straws containing $40 \mu \mathrm{l}$ freezing medium separated by an air bubble from $440 \mu \mathrm{l}$ sucrose solution. The straws were frozen rapidly in the vapour about $1 \mathrm{~cm}$ above the surface of liquid nitrogen. The post-thaw viability was substantially better after sucrose dilution at $20^{\circ} \mathrm{C}$ than at $36^{\circ} \mathrm{C}$. Mixing the freezing medium with the sucrose diluent immediately after thawing further improved the rate of survival relative to mixing just before freezing $(P<0.001)$. The best survival was obtained when the freezing medium contained $3.0 \mathrm{M}$-glycerol $+0.25 \mathrm{M}$-sucrose; it was mixed with the diluent after thawing and the glycerol was removed at $20^{\circ} \mathrm{C}$. Under such conditions the sucrose concentration in the diluent had no significant effect on the rate of development $(0.5 \mathrm{M}, 69 \% ; 1.0 \mathrm{M}, 73 \%$; $1.5 \mathrm{M}, 64 \%$ ).

The results show that during sucrose dilution the temperature should be strictly controlled and suggest that intracellular and extracellular concentrations of glycerol are important in the cryoprotection of embryos.
\end{abstract}

\section{Introduction}

The occurrence of intracellular ice formation during freezing can be minimized by dehydration of cells (Mazur, 1970). The early success in cryopreservation of mouse embryos depended on the use of cryoprotectants and on the partial dehydration of cells by slow freezing rates (Whittingham, Leibo \& Mazur, 1972; Wilmut, 1972). Cryoprotectant-permeated embryos can survive fast freezing rates when they are partly dehydrated by sucrose before freezing (Nguyen, Renard \& Garnier, 1983; Renard, Bui-Xuan-Nguyen \& Garnier, 1984; Takeda, Elsden \& Seidel, 1984). Further development of procedures to freeze embryos without the need for precisely controlled freezing rates and for tedious stepwise post-thaw dilution is of both practical and theoretical importance. These simple techniques would allow a much more widespread use of frozen embryos if they provided similar or higher survival rates.

Embryos frozen in methanol solutions can be transferred directly into physiological medium after thawing (Rall, Czlonkowska, Barton \& Polge, 1984). Our preliminary experience showed that methanol did not provide sufficient protection for embryos frozen rapidly in liquid nitrogen vapour. Direct transfer from DMSO solutions does not affect the viability of Day-4 mouse embryos (Rall, Wood \& Kirby, 1984), but severely impairs the developmental potential of Day-2 mouse embryos (Whittingham \& Wales, 1969) and Day-7 cow embryos (Willadsen, Polge \& Rowson, 1978). 
The concepts of single-step sucrose dilution of cryoprotectant from embryos (Leibo \& Mazur, 1978) and of freezing embryos in plastic straws (Tsunoda \& Sugie, 1977; Massip et al., 1979) were utilized by Leibo, West \& Perry (1982) and Renard, Heyman \& Ozil (1982), for in-straw sucrose dilution. The optimal temperature requirements for this procedure have not been defined and very little is known about the toxicity of sucrose to embryos at ambient temperatures above $20^{\circ} \mathrm{C}$. The present experiments were designed to study the toxic effects of sucrose at three environmental temperatures and to find optimal conditions for in-straw sucrose dilution of mouse embryos frozen rapidly using a procedure based on that of Takeda $e t$ al. (1984).

\section{Materials and Methods}

\section{Superovulation and collection of embryos}

Randomly bred WEHI female mice, 6-8 weeks of age, were superovulated by intraperitoneal injection of 5 i.u. PMSG and 5 i.u. hCG $46 \mathrm{~h}$ apart. The females were individually paired with males at the time of the hCG injection and checked for vaginal plugs the next morning. On the third day (65-70 $\mathrm{h}$ after the hCG injection) the mated females were killed, their oviducts and uteri were excised and flushed with Dulbecco's phosphate-buffered saline (PBS) supplemented with 5\% fetal calf serum (FCS). The morphologically normal 8- to 16-cell embryos were pooled and then washed in three changes of medium.

\section{Studies on toxicity of sucrose to fresh embryos}

The effect of sucrose on the developmental potential of freshly collected embryos was investigated in factorial experiments. A total of 1770 embryos was exposed for 10, 20 or 30 min to various sucrose concentrations $(0,0.25,0.5,1.0$ or $2.0 \mathrm{M}$ in Exps 1 and $2 ; 0,0.5,1.0$ or $1.5 \mathrm{M}$ in Exp. 3) at $20^{\circ} \mathrm{C}$ (Exp. 1), at $25^{\circ} \mathrm{C}$ (Exp. 2) or at $36^{\circ} \mathrm{C}$ (Exp. 3). The sucrose solutions were prepared in PBS $+5 \%$ FCS.

The experimental unit was a group of 10 (Exps 1 and 2) or 12 (Exp. 3) embryos randomly allocated to treatments. The experimental design was a randomized block with 3, 4 or 5 replications (Exps 2, 1 and 3, respectively). After exposure to sucrose, the embryos were washed in PBS + 5\% FCS, cultured for 2 days and the number of embryos developing to blastocyst stage was recorded.

\section{Studies on removal of glycerol from frozen-thawed embryos}

Freezing and thawing procedures. The embryos were frozen in plastic straws (Tsunoda \& Sugie, 1977; Massip et al., 1979) using procedures based on those of Takeda et al. (1984). The following fractions were aspirated into a $0.5 \mathrm{ml}$ Cassou straw: $440 \mu \mathrm{l}$ diluent (sucrose solution), $20 \mu \mathrm{l}$ air and $40 \mu \mathrm{l}$ freezing medium. The sucrose solution and the freezing medium were prepared in PBS $+5 \%$ FCS. A group of 20 embryos was pipetted from PBS $+5 \%$ FCS into a microdrop of freezing medium and then into the identical medium within a straw. The straw was heat-sealed at both ends, and after $10 \mathrm{~min}$ equilibration, the embryos were frozen by placing the straw horizontally in the vapour about $1 \mathrm{~cm}$ above the surface of liquid nitrogen (about $-180^{\circ} \mathrm{C}$ ) in an open container. The cooling rate from 20 to $-20^{\circ} \mathrm{C}$ was $-140^{\circ} \mathrm{C} / \mathrm{min}$. A medium containing $3.0 \mathrm{M}$-glycerol $+0.25 \mathrm{M}-$ sucrose supercooled to about $-26^{\circ} \mathrm{C}$ then warmed up to $-20^{\circ} \mathrm{C}$ as ice formed spontaneously. The mean freezing rates between $-30,-90,-120$ and $-150^{\circ} \mathrm{C}$ were, respectively, $-140,-127$ and $-80^{\circ} \mathrm{C} / \mathrm{min}$. After $7-10 \mathrm{~min}$ in the vapour, the straws were transferred into liquid nitrogen and stored for periods ranging from 5 days to 2 months. The freezing medium and the sucrose diluent were mixed immediately before freezing (Exps 4, 5 and 6) or after thawing (Exps 6 and 7) by shaking the straw like a clinical thermometer (Leibo et al., 1982; Renard et al., 1982). The straws 
were thawed in a waterbath without agitation until the ice melted. The embryos were left for $10 \mathrm{~min}$ to allow glycerol removal before being pipetted into PBS $+5 \%$ FCS for another 10-20 min and then were cultured for 2 days. The number of embryos developing to blastocysts in culture was expressed as the proportion of those frozen. The experimental unit was a group of 20 embryos frozen in a straw.

Experimental designs. Experiments 4 and 5 were designed to study the effect of the following factors: sucrose concentration for in-straw dilution $(0.25,0.5,1.0$ or $1.5 \mathrm{M})$, temperature of the thawing bath $\left(20\right.$ or $\left.36^{\circ} \mathrm{C}\right)$ and temperature during glycerol removal $\left(20\right.$ or $\left.36^{\circ} \mathrm{C}\right)$. The freezing medium (2.0 M-glycerol + $0.25 \mathrm{M}$-sucrose in Exp. 4 and $3.0 \mathrm{M}$-glycerol $+0.25 \mathrm{M}$-sucrose in Exp. 5) was mixed with the sucrose diluent just before freezing. After thawing, the glycerol was removed at controlled temperature either by leaving the straw in the thawing bath or placing it into another bath of different temperature $\left(20\right.$ or $\left.36^{\circ} \mathrm{C}\right)$. This temperature was kept constant for $10 \mathrm{~min}$, and the embryos were recovered from the straw at $20^{\circ} \mathrm{C}$ or on a $36^{\circ} \mathrm{C}$ warm stage. Experiments 4 and 5 each had two replications in randomized blocks.

Experiment 6 was a $2 \times 3$ factorial in 3 randomized blocks. A total of 360 embryos was frozen to investigate the effect of the time of mixing the freezing medium ( $3.0 \mathrm{M}$-glycerol $+0.25 \mathrm{M}$-sucrose) with the sucrose diluent (just before freezing or immediately after thawing) at three levels of sucrose concentration $(0.5,1.0$ or $1.5 \mathrm{M})$. The straws were thawed at $36^{\circ} \mathrm{C}$ and the glycerol was removed at $20^{\circ} \mathrm{C}$.

Experiment 7 was a $3 \times 3$ factorial with 3 randomized blocks. A total of 540 embryos was frozen to study the effect of the glycerol concentration in the freezing medium $(2 \cdot 0,3 \cdot 0$ or $4 \cdot 0 \mathrm{M})$ and the sucrose concentration in the diluent $(0.5,1.0$ or $1.5 \mathrm{M})$. In addition to glycerol, the freezing medium also contained $0.25 \mathrm{M}$-sucrose. The straws were thawed in a $36^{\circ} \mathrm{C}$ water bath. The freezing medium and the diluent were mixed after thawing and left at $20^{\circ} \mathrm{C}$ during glycerol removal.

\section{Culture of embryos}

The embryos were cultured in Whitten's medium (Whitten, 1971) supplemented with $10 \mu \mathrm{M}$ EDTA (Abramczuk, Solter \& Koprowski, 1977) in an humidified atmosphere of $5 \% \mathrm{CO}_{2}, 5 \% \mathrm{O}_{2}$ and $90 \% \mathrm{~N}_{2}$ at $37^{\circ} \mathrm{C}$ for $48 \mathrm{~h}$. All embryos recovered after experimental treatments were cultured irrespective of their morphological integrity.

\section{Statistical analysis}

After angular transformation (Mosteller \& Youtz, 1961) the data were subjected to analysis of variance and when appropriate the regression of response on treatment was examined by orthogonal polynomial coefficients. The theoretical error variance $(821 / \mathrm{n})$ was used to test the treatment effects, except in Exp. 5 in which the experimental error differed significantly from the theoretical estimate. The significance of orthogonal comparisons amongst treatment means was established by the protected LSD method. The overall survival rates of embryos in Exps 4 and 5 were compared by $\chi^{2}$ test.

\section{Results}

\section{Effects of sucrose on fresh embryos}

The results of Exps 1, 2 and 3 are shown in Table 1. In each experiment the effect of sucrose concentration was significant $(P<0.001)$. The regression of sucrose concentration on response involved significant $(P<0.001)$ linear (Exps 1, 2 and 3), quadratic (Exps 1 and 2) and cubic elements (Exps 1, 2 and 3). 
Table 1. The effect of concentration of sucrose and duration of exposure at three temperatures $\left(20,25\right.$ and $\left.36^{\circ} \mathrm{C}\right)$ on the percentage of fresh embryos $(n)$ developing to the blastocyst stage (Exps 1,2 and 3)

\begin{tabular}{|c|c|c|c|c|c|c|c|}
\hline \multirow[b]{2}{*}{ Exp. } & \multirow[b]{2}{*}{ Temp. $\left({ }^{\circ} \mathrm{C}\right)$} & \multirow[b]{2}{*}{$n$} & \multirow{2}{*}{$\begin{array}{l}\text { Sucrose } \\
\text { conc. (M) }\end{array}$} & \multicolumn{3}{|c|}{ Exposure period (min) } & \multirow[b]{2}{*}{ Mean } \\
\hline & & & & 10 & 20 & 30 & \\
\hline \multirow[t]{2}{*}{1} & 20 & 40 & $\begin{array}{l}0 \\
0.25 \\
0.5 \\
1.0 \\
2.0\end{array}$ & $\begin{array}{l}88 \\
93 \\
95 \\
93 \\
35\end{array}$ & $\begin{array}{r}90 \\
90 \\
90 \\
80 \\
0\end{array}$ & $\begin{array}{r}93 \\
93 \\
85 \\
95 \\
0\end{array}$ & $\begin{array}{l}90^{\mathrm{a}} \\
92^{\mathrm{a}} \\
90^{\mathrm{a}} \\
89^{\mathrm{a}} \\
12^{\mathrm{b}}\end{array}$ \\
\hline & & & Mean & 80 & 70 & 73 & 75 \\
\hline \multirow[t]{2}{*}{2} & 25 & 30 & $\begin{array}{l}0 \\
0.25 \\
0 \cdot 5 \\
1 \cdot 0 \\
2 \cdot 0\end{array}$ & $\begin{array}{r}97 \\
90 \\
93 \\
90 \\
0\end{array}$ & $\begin{array}{r}100 \\
80 \\
93 \\
83 \\
0\end{array}$ & $\begin{array}{r}100 \\
87 \\
90 \\
73 \\
0\end{array}$ & $\begin{array}{c}99^{\mathrm{a}} \\
86^{\mathrm{ab}} \\
92^{\mathrm{ab}} \\
82^{\mathrm{b}} \\
0^{\mathrm{c}}\end{array}$ \\
\hline & & & Mean & 74 & 71 & 70 & 72 \\
\hline \multirow[t]{2}{*}{3} & 36 & 60 & $\begin{array}{l}0 \\
0.5 \\
1.0 \\
1.5\end{array}$ & $\begin{array}{r}97 \\
92 \\
10 \\
3\end{array}$ & $\begin{array}{r}93 \\
88 \\
3 \\
0\end{array}$ & $\begin{array}{r}92 \\
80 \\
0 \\
0\end{array}$ & $\begin{array}{r}94^{\mathrm{d}} \\
87^{\mathrm{e}} \\
4^{\mathrm{f}} \\
1^{\mathrm{f}}\end{array}$ \\
\hline & & & Mean & 50 & 46 & 43 & 47 \\
\hline
\end{tabular}

Means within the same experiment with different superscripts differ significantly (a,b,c, $P<0.001$; d,e,f, $P<0.05$ ).

At $20^{\circ} \mathrm{C}$, exposure to $1.0 \mathrm{M}$ or lower concentrations of sucrose had no adverse effects on the developmental potential of embryos. In $2.0 \mathrm{M}$-sucrose the mean viability was reduced from 90.2 to $12 \%(P<0.001)$ and the effect of duration of exposure was significant $(P<0.001)$.

At $25^{\circ} \mathrm{C}$ after exposure to $0,0 \cdot 25,0 \cdot 5,1 \cdot 0$ or $2 \cdot 0 \mathrm{M}$ solutions of sucrose, $99,86,92,82$ and $0 \%$ of the embryos respectively remained viable. The reduction compared to control was significant at concentrations of 1.0 and $1.5 \mathrm{M}(P<0.001)$. The effect of duration of exposure was not significant $(\mathrm{F}<1)$.

At $36^{\circ} \mathrm{C}$ the viability of embryos was depressed to $87 \%$ by $0.5 \mathrm{M}$ sucrose (control $94 \%$, $P<0.05)$ and further reduced to 4 and $1 \%$ by 1.0 and $1.5 \mathrm{M}$-sucrose respectively $(P<0.001)$. At all concentrations the increase in exposure period caused some decrease in the developmental potential; overall this effect was significant $(P<0.05)$.

\section{Removal of glycerol from frozen-thawed embryos}

On average $90-95 \%$ of embryos frozen were recovered after thawing.

Effects of thawing rate, temperature during glycerol removal and concentration of sucrose. In Exps 4 and 5, in which the freezing medium and the sucrose diluent were mixed immediately before freezing, the viability of frozen-thawed embryos was better when the glycerol concentration in the freezing medium was $3.0 \mathrm{M}$ than when it was $2.0 \mathrm{M}$ (Exps 5 and $4,16 \%$ and $0.03 \%$ respectively, $P<0.001$ ). In Exp. 4 no more than 1 frozen-thawed embryo developed from any treatment group. In Exp. 5 the thawing temperature did not affect the survival rate $\left(20^{\circ} \mathrm{C}, 15 \% ; 36^{\circ} \mathrm{C}, 17.2 \%\right)$ and did not interact with other factors $(\mathrm{F}<1)$. The mean development rates over replicates and thawing temperatures are shown in Table 2 . The effects of temperature during glycerol removal and sucrose concentration in the diluent were highly significant $(P<0.001)$. The viability was markedly 
Table 2. The effect of temperature during glycerol removal and concentration of sucrose diluent on the percentage of frozenthawed embryos $(n=80)$ developing to blastocyst stage (Exp. 5)

\begin{tabular}{lcccrr}
\hline Temperature & \multicolumn{4}{c}{ Concentration of sucrose (M) } \\
during \\
\cline { 2 - 5 } dilution & 0.25 & 0.5 & 1.0 & 1.5 & Mean \\
\hline $20^{\circ} \mathrm{C}$ & $1^{\mathrm{a}}$ & $10^{\mathrm{b}}$ & $51^{\mathrm{c}}$ & $39^{\mathrm{d}}$ & 25.3 \\
$36^{\circ} \mathrm{C}$ & $0^{\mathrm{a}}$ & $9^{\mathrm{b}}$ & $18^{\mathrm{b}}$ & $1^{\mathrm{a}}$ & 6.9 \\
Mean & 0.6 & 9.3 & 34.4 & 20 & 16.1 \\
\hline
\end{tabular}

Means with different superscripts are significantly $(P<0.05)$ different.

higher after removing the glycerol at $20^{\circ} \mathrm{C}(25 \cdot 3 \%, 81 / 320)$ than at $37^{\circ} \mathrm{C}(6 \cdot 9 \%, 22 / 320)$. At both glycerol removal temperatures the best survival was achieved when the diluent contained $1.0 \mathrm{M}-$ sucrose. There was a significant $(P<0.01)$ interaction between the two factors; the effect of glycerol removal temperature was important when the diluent contained 1.0 or $1.5 \mathrm{M}$-sucrose, but not at 0.25 or $0.5 \mathrm{M}$ concentration.

Effects of time of mixing and sucrose concentration in the diluent. In Exp. 6 the time of mixing and the sucrose concentration of the diluent significantly $(P<0.001$ and $P<0.005$ respectively) affected the developmental potential of frozen-thawed embryos (Table 3). Mixing the diluent and freezing medium after thawing resulted in substantially higher viability $(65 \%, 117 / 180)$ than did mixing before freezing $(37 \%, 67 / 180)$. There was an interaction between the two factors $(P<0 \cdot 05)$. The effect of sucrose concentration was significant when the mixing was done before freezing $(P<0.001)$, but not when it was done after thawing $(P>0.1)$.

Table 3. The effects of time of mixing the freezing medium ( $3.0 \mathrm{M}$-glycerol $+0.25 \mathrm{M}$-sucrose) and diluent, and concentration of sucrose diluent on the percentage of frozenthawed embryos $(n=60)$ developing to the blastocyst stage (Exp. 6)

\begin{tabular}{lllll}
\hline & \multicolumn{3}{c}{ Sucrose conc. (M) } & \\
\cline { 2 - 4 } Time of mixing & 0.5 & $1 \cdot 0$ & $1 \cdot 5$ & Mean \\
\hline Before freezing & $18^{\mathrm{a}}$ & $40^{\mathrm{b}}$ & $53^{\mathrm{c}}$ & 37 \\
After thawing & 58 & 73 & 63 & 65 \\
Mean & 38 & 56 & 58 & 51 \\
\hline
\end{tabular}

Means within the same row with different superscripts differ significantly $(P<0 \cdot 01)$.

Effect of glycerol concentration in the freezing medium and sucrose concentration in the diluent. In Exp. 7, in which the freezing medium and the sucrose diluent were mixed after thawing, the concentration of glycerol in the freezing medium had a significant $(P<0.001)$ effect on the viability of embryos (Table 4). At glycerol concentrations of $2 \cdot 0,3.0$ and $4 \cdot 0 \mathrm{M}$, respectively, 26, 73 and $60 \%$ of the frozen-thawed embryos developed in culture. There was an interaction between the glycerol concentration of the freezing medium and the sucrose concentration of the diluent $(P<0 \cdot 025)$. The effect of sucrose concentration was significant $(P<0.025)$ for embryos frozen in $2.0 \mathrm{M}$-glycerol, but not for those frozen in 3.0 or $4.0 \mathrm{M}-$ glycerol. 
Table 4. The effect of concentration of glycerol in the freezing medium and the concentration of sucrose in the diluent on the percentage of frozen thawed embryos $(n=60)$ developing to the blastocyst stage (Exp. 7)

\begin{tabular}{lcccc}
\hline \multirow{2}{*}{$\begin{array}{l}\text { Glycerol conc. (M) in } \\
\text { freezing medium }\end{array}$} & \multicolumn{3}{c}{ Sucrose conc. (M) } \\
\cline { 2 - 3 } & $0 \cdot 5$ & $1 \cdot 0$ & $1 \cdot 5$ & Mean \\
\hline $2 \cdot 0$ & 20 & 18 & 38 & $26^{\mathrm{a}}$ \\
$3 \cdot 0$ & 80 & 73 & 65 & $73^{\mathrm{b}}$ \\
$4 \cdot 0$ & 57 & 57 & 67 & $60^{\mathrm{b}}$ \\
Mean & 52 & 49 & 57 & 53 \\
\hline
\end{tabular}

Means within the same column with different superscripts are significantly $(P<0.001)$ different.

\section{Discussion}

Renard et al. (1982) and Leibo (1983) tested the toxicity of sucrose using small numbers of cattle embryos and found that, at lower concentrations than studied here, there were no detrimental effects. Kasai, Niwa \& Iritani (1981) studied the effect of exposing mouse morulae to $0.75 \mathrm{M}$-sucrose solution at different temperatures. Compared to the PBS control, the sucrose solution had a protective effect at $0^{\circ} \mathrm{C}$, but at $20^{\circ} \mathrm{C}$ it reduced the viability following exposures for more than $3 \mathrm{~h}$. In the present experiments, mouse embryos lost their developmental potential with accelerated rapidity (quadratic and higher regression components) as the concentration of sucrose was increased from zero to $2.0 \mathrm{M}$. This sharp decline occurred at lower concentrations after longer exposure periods and at higher temperatures. It became evident that the toxic effects of sucrose depend not only on its concentration and the duration of exposure, but also on the temperature. This finding is in agreement with the results of Kasai et al. (1981).

In the present embryo freezing procedure sucrose has two roles. When included in the freezing medium, sucrose causes the embryos to shrink by losing water, so that intracellular ice formation is reduced (Mazur, 1970) and the embryos can be frozen rapidly and without seeding (Nguyen et al., 1984; Renard et al., 1984; Takeda et al., 1984). The work of these authors indicated that the optimum concentration of sucrose in the freezing medium is around $0.25-0.5 \mathrm{M}$.

The mechanistic basis of sucrose dilution is described by Leibo (1984) and Schneider \& Mazur (1984). The sucrose solution controls the degree of swelling during cryoprotectant removal by counteracting the initially high intracellular osmolarity of the cryoprotectant-permeated cells. As the cryoprotectant leaves the cells, to maintain osmotic equilibrium, the embryos will lose water and shrink. In physiological medium the cells regain their original volume. A wide range of conditions has been used for removal of cryoprotectant by sucrose dilution from frozen-thawed embryos. The molarity of sucrose solutions has varied from 0.25 to $2.0 \mathrm{M}$. The rate of dilution from about 5- to 20 -fold and the temperature from 20 to $37^{\circ} \mathrm{C}$ (Leibo, 1983, 1984; Merry, Allen, Krag \& Wright, 1983; Chupin, Florin \& Procureur, 1984; Takeda et al., 1984). Leibo (1984) found that under field conditions the pregnancy rate decreased sharply when the ambient temperature during sucrose dilution exceeded $25^{\circ} \mathrm{C}$, and suggested that the embryos may be sensitive to high concentrations of sucrose at elevated temperatures. The present results for freshly collected embryos showed that the higher the temperature, the more sensitive the embryos were to sucrose. These findings were confirmed in experiments with frozen-thawed embryos; the increased temperature had adverse effects on embryos diluted with the two higher concentrations of sucrose.

The chances of survival were improved by removing the glycerol at $20^{\circ} \mathrm{C}$ and mixing the freezing medium with the diluent after thawing rather than just before freezing. The effect of time of 
mixing can be explained by the changes in the glycerol concentration. After mixing there was an 11-fold decrease in the extracellular concentration; however, the reduction in the intracellular glycerol content must have been much smaller. The reason for this assumption is that only about $1 \mathrm{sec}$ elapsed between mixing and placing the straw in liquid nitrogen vapour, after which glycerol permeability of the embryos decreased sharply because of its dependence on the temperature (Schneider \& Mazur, 1984). The suggestion that the effect of time of mixing is mainly due to changes in extracellular concentration of glycerol is in accord with the conclusion of Mazur (1977) that the external cell surface is especially vulnerable to electrolyte damage and must be protected during freezing.

The results of Exps 4, 5 and 7 show that a higher concentration of glycerol is necessary to protect the embryos during rapid freezing in liquid nitrogen vapour than is necessary for freezing at a controlled rate (Leibo \& Mazur, 1974). Under the conditions tested here, the optimum concentration of sucrose for cryoprotectant removal did not increase at higher concentrations of glycerol.

The effect of sucrose concentration in the range $0.5-1.5 \mathrm{M}$ was significant only when the embryos were mixed with the diluent before freezing or the freezing medium contained $2.0 \mathrm{M}$ glycerol. In the former case the sucrose concentration in the diluent largely affected the composition of the medium surrounding the embryos during freezing and thawing. This is more likely to account for the effect of sucrose concentration than the osmotic behaviour of embryos during glycerol removal, because there was no significant effect on embryos frozen in 3.0 or $4.0 \mathrm{M}$-glycerol and mixed after thawing. When the freezing medium contained $2.0 \mathrm{M}$-glycerol the effect of sucrose concentration in the diluent was caused probably by the fact that these solutions left a coating on the wall of the straw during loading which increased the sucrose concentration of the freezing medium. These alterations did not affect the viability of embryos frozen in higher concentrations of glycerol.

Some of the present experiments are directly comparable with those of Takeda et al. (1984). The survival rate reported here is lower, especially when the freezing medium contained $2.0 \mathrm{M}$-glycerol, or the embryos were exposed to $2 \cdot 0 \mathrm{M}$-sucrose. This cannot be completely explained by differences in the method of freezing, culture medium and definition of survival rate. Takeda et al. (1984) did not specify whether survival rate was calculated in relation to the number of embryos frozen, recovered after thawing, or intact after thawing. In the present experiments the embryos were frozen in liquid nitrogen vapour because many straws cracked after direct transfer into liquid nitrogen.

In summary, under the conditions tested, the rapidly frozen embryos survive just as well when thawed in a 20 or $36^{\circ} \mathrm{C}$ water bath; however, when the latter is used the straw should be placed in a $20^{\circ} \mathrm{C}$ environment during the sucrose dilution. Optimal results were obtained when the freezing medium contained $3.0 \mathrm{M}$-glycerol $+0.25 \mathrm{M}$-sucrose and was mixed with the sucrose diluent after thawing. Under these conditions the sucrose concentration of the diluent did not affect the results significantly within the range of 0.5 to $1.5 \mathrm{M}$.

The skilful assistance of Ms Heather McDonagh in the collection of embryos is gratefully acknowledged.

\section{References}

Abramczuk, J., Solter, D. \& Koprowski, H. (1977) The beneficial effect of EDTA on development of mouse one-cell embryos in chemically defined medium. Devl Biol. 61, $378-383$.
Chupin, D., Florin, B. \& Procureur, R. (1984) Comparison of two methods for one-step in-straw thawing and direct transfer of cattle blastocysts. Theriogenology 21, 455-459. 
Kasai, M., Niwa, K. \& Iritani, A. (1981) Effects of various cryoprotective agents on the survival of unfrozen and frozen mouse embryos. J. Reprod. Fert. 63, 175-180.

Leibo, S.P. (1983) A one-step in situ dilution method for frozen-thawed bovine embryos. Cryo-Letters 4, $387-400$.

Leibo, S.P. (1984) A one-step method for direct nonsurgical transfer of frozen-thawed bovine embryos. Theriogenology 21, 767-790.

Leibo, S.P. \& Mazur, P. (1974) Survival of frozenthawed mouse embryos as a function of glycerol permeation. Cryobiology 11, 559-560, Abstr.

Leibo, S.P. \& Mazur, P. (1978) Methods for the preservation of mammalian embryos by freezing. In Methods in Mammalian Reproduction, pp. 179-201. Ed. J. C. Daniel, Jr. Academic Press, New York.

Leibo, S.P., West, A.W., III \& Perry, B. (1982) A one-step method for direct nonsurgical transfer of frozen-thawed bovine embryos. II. Applied studies. Cryobiology 19, 674, Abstr.

Massip, A., Van der Zwalmen, P., Ectors, F., De Coster, R., D'Ieteren, G. \& Hanzen, C. (1979) Deep freezing of cattle embryos in glass ampules or French straws. Theriogenology 12, 79-84.

Mazur, P. (1970) Cryobiology: the freezing of biological systems. Science, N.Y. 168, 939-949.

Mazur, P. (1977) Slow-freezing injury in mammalian cells. In The Freezing of Mammalian Embryos (Ciba Fdn Symp. No. 52), pp. 19 48. Eds K. Elliott \& J. Whelan. Elsevier/North Holland, Amsterdam.

Merry, D.A., Allen, R.L., Krag, K. \& Wright, R.W., Jr (1983) Sucrose dilution of frozen mouse embryos: interaction of glycerol and sucrose concentrations. Theriogenology 20, 325-332.

Mosteller, F, \& Youtz, C. (1961) Tables of the FreemanTukey transformations for the binomial and Poisson distributions. Biometrika 48, 433-440.

Nguyen, B.X., Renard, J.P. \& Garnier, V. (1983) Rapid freezing and thawing of 2-cell-stage rabbit embryos after partial dehydration at room temperature. Cryobiology 20, 742, Abstr.

Rall, W.F., Czlonkowska, M., Barton, S.C. \& Polge, C. (1984) Cryoprotection of Day-4 mouse embryos by methanol. J. Reprod. Fert. 70, 293-300.
Rall, W.F., Wood, M.J. \& Kirby, C. (1984) The transfer of frozen-thawed mouse embryos in dimethyl sulfoxide: effect of dilution and short-term culture. Cryobiology 21, 710-711, Abstr.

Renard, J.-P., Heyman, Y. \& Ozil, J.-P. (1982) Congélation de l'embryon bovin: une nouvelle méthode de décongélation pour le transfert cervical d'embryons conditionnés une seule fois en paillettes. Annls Méd. Vét. 126, 23-32.

Renard, J.-P., Bui-Xuan-Nguyen, \& Garnier, V. (1984) Two-step freezing of two-cell rabbit embryos after partial dehydration at room temperature. J. Reprod. Fert. 71, 573-580.

Schneider, U. \& Mazur, P. (1984) Osmotic consequences of cryoprotectant permeability and its relation to survival of frozen-thawed embryos. Theriogenology 21, 68-79.

Takeda, T., Elsden, R.P. \& Seidel, G.E., Jr (1984) Cryopreservation of mouse embryos by direct plunging into liquid nitrogen. Theriogenology 21, 266, Abstr.

Tsunoda, Y. \& Sugie, T. (1977) Survival of rabbit eggs preserved in plastic straws in liquid nitrogen. $J$. Reprod. Fert. 49, 173-174.

Whitten, W.K. (1971) Nutrient requirements for the culture of pre-implantation embryos in vitro. $A d v$. Biosci. 6, 129-141.

Whittingham, D.G. \& Wales, R.G. (1969) Storage of twocell mouse embryos in vitro. Aust. J. biol. Sci. 22, 1065-1068.

Whittingham, D.G., Leibo, S.P. \& Mazur, P. (1972) Survival of mouse embryos frozen to $-196^{\circ}$ and $-269^{\circ}$ C. Science, N.Y. 178, $411-414$.

Willadsen, S., Polge, C. \& Rowson, L.E.A. (1978) The viability of deep-frozen cow embryos. J. Reprod. Fert. 52, 391-393.

Wilmut, I. (1972) The effect of cooling rate, warming rate, cryoprotective agent and stage of development on survival of mouse embryos during freezing and thawing. Life Sci. 11, 1071-1079.

Received 31 May 1985 